\title{
Supersonic STOVL Aircraft With Turbine Bypass/Turbo-Compressor Engines
}

Leo C. Franciscus and Roger W. Luidens

Lewis Research Center

Cleveland, Ohio

Prepared for the

Twentieth Joint Propulsion Conference cosponsored by the AIAA, SAE, and ASME

Cincinnati, Ohio June 11-13, 1984

\section{N/SA}


SUPERSONIC STOVL AIRCRAFT WITH

TURBINE BYPASS/TURBO-.COMPRESSOR ENGINES

by

Leo $C$ Franciscus and Roger $w$. Luidens $=$

National Aeronautics and Space Administration

Lewis Research Center

Cleveland, Ohio 44135

\section{ABSTRACT}

Engine performance and mission studies were performed to compare three propulsion systems for a Mach 2 STOVL fighter The three propulsion systems are (1) turbine bypass engine with a turbo-compressor used for STOVL only, (2) turbine bypass engine with a turbo--compressor for both STOVL and thrust during forward flight, and (3) mixed flow afterburning turbofan with a remote burner 1 ift system. In the first system, (1), the main engines have afterburners and the turbo. compressors use afterburning during STOVL In the second system, (2), the turbine bypass engines are dry and the turbo-compressors have afterburners

The mission used in the study is a deck launched intercept mission The aircraft used is the NASA-Langley twin boom concept having a takeoff gross weight of $470001 \mathrm{bm}$.

The results of the study indicate that large improvements in combat time ( 50 to 400 percent) are possible when the turbo-compressors are used for both lift and thrust for forward flight

\section{NOMENCLATURE}

$\begin{array}{ll}\text { BPR } & \text { bypass ratio } \\ \text { CET } & \text { combustor exit temperature, oR } \\ F & \text { thrust } \\ \text { FPR } & \text { fan pressure ratio } \\ \mathrm{ft} & \text { feet } \\ \mathrm{hr} & \text { hour } \\ \text { Ibf } & \text { pounds force } \\ \text { Ibm } & \text { pounds mass } \\ \text { MAX } & \text { maximum } \\ \text { min } & \text { minute } \\ \text { n.mi } & \text { nautical miles } \\ \text { OPR } & \text { engine overali pressure ratio } \\ R & \text { degree Rankine } \\ \text { SeC } & \text { second } \\ \text { SFC } & \text { specific fuel consumption, } 1 \mathrm{bm} / \mathrm{hr} / 1 \mathrm{bf} \\ \text { TAUG } & \text { augmentor temperature, OR } \\ W & \text { Weight, } 1 \mathrm{bm} \\ \text { Wa } & \text { engine airflow, } 1 \mathrm{bm} / \mathrm{sec} \\ W G & \text { aircraft gross weight, } 1 \mathrm{bm}\end{array}$

Subscripts

$\begin{array}{ll}\text { ENG } & \text { engine } \\ \text { MAX } & \text { maxtmum }\end{array}$

\section{INTRODUCTION}

Providing a short takeoff and vertical landing (STOVL) capability for a supersonic aircraft poses many challenges in propulsion system design A wide variety of propulsion concepts have been studied for providing jet lift including ejectors, remote burners, and fans and dedicated 1 ift engines 13 In a 11 of these concepts, the lift system represents a penalty in weight for the rest of the aircraft mission Also, the aircraft aerodynamics are compromised due to the added volume needed to house the lift system. The tandem fan concept is an approach that is being studied in which the main engine provides both 1 ift and thrust 4-5 This concept employs a dual fan arrangement in which the front fan discharge air is diverted downward during vertical operation and converts to a conventional turbofan for forward flight

The turbojet would be a simple, compact engine for a supersonic STOVL aircraft An undesirable feature of the turbojet for this application is that hot jet exhaust gas must be ducted to the forward lift system Another problem is that it is not well suited for air craft that require wide variations in throttle for extended periods of time and whose missions require significant supersonic and subsonic range capabilities

A means of adapting the turbojet for these requirements is provided by the turbine bypass engine (TBE) In this concept shown schemati. cally in figure 1, a variable bypass system is employed to improve the turbojet performance for wide variations in throttle settings The bypass system directs some of the compressor discharge air around the burner and turbine, and reinjects it into the nozzle. At maximum dry power (high turbine inlet temperature) operation the amount of bypass air is at a maximum and at low power the bypass fraction is reduced or the bypass is turned off completely This concept was first studied by Boeing in their commercial supersonic transport studies A later study of this concept for a commercial supersonic transport is reported in reference 6

More recentiy, the TBE is being studied for military aircraft The bypass system is an attractive means of powering $11 \mathrm{ft}$ systems for STOVL aircraft In reference 3 , two lift system powered by the TBE bypass air were studied a remote burner system and a remote turbocompressor lift system. The results reported in reference 3 indicate the TBE/turbo-compressor is 
an attractive system for STOVL aircraft The turbo-compressor provides an adequate thrust level for easier airplane thrust balance It also provides a source of power for the reaction control systems.

An additional feature of the TBE/turbo. compressor that deserves study is the use of the turbo-compressor for both STOVL operation and thrust for the rest of the mission. This would have the advantage of reducing the main TBE engine size Also, both the single spool TBE and the turbo compressor are relatively simple turbomachines

With these motivations, an in house study has been initiated at NASA Lewis to quantita. tively determine the benefits of extending the turbo-compressor duty to horizontal flight

In this study, three propulston systems for STOVL aircraft are being studied: (1) TBE with turbo-compressor for STOVL only, TBE/(TC.-STOVL only), (2) TBE with turbo compressor for both STOVL and cruise, TBE/(TC..STOVL \& cruise), and a mixed flow afterburning turbofan with a remote burner (TF/RALS) Engine performance, weight, and mission analysis are being performed for these three concepts The potential of the engines is assessed in terms of mission radius and combat time This paper provides some pre. liminary results of these studies

\section{DESCRIPTION OF THE ENGINES}

Schematics of the three propulsion systems are shown in figure 2 The TBE engine is a single spool turbojet The turbofan is a mixed flow, two spool engine. The turbo.compressor has an axi-centrifugal fan driven by a two stage axial turbine The turbine is driven by high pressure compressor bypass air from the TBE engines The turbo compressor and the turbofan are equipped with afterburners in the TBE/(TC.STOVL only) system, the TBE's are equipped with afterburners In the TBE/(TC.STOVL \& cruise) system, the TBE engines are dry

The TBE/(TC.-STOVL only) and the TBE/(TC.-STOVL \& cruise) propulsion systems and their modes of operation are shown in figures 3 and 4 The modes of operation for the TF/RALS system are the same as for the TBE/(TC..STOVL only) system. As shown in figure 3 for the TBE/(TC.STOVL on ly) system, the TBE engines are at maximum after burning power during the takeoff roll, (1), and the turbo.compressors are inoperative Note that all of the bypass air is directed into the main engine nozzle At 1 ift.off, (2), the bypass air is directed to the turbo-compressors which operate at maximum afterburner power to provide the pitch up force for $11 \mathrm{ft}$-off The main engine nozzles are directed at a downward angle oper ation of the turbo-compressors would have to be initiated before $13 \mathrm{ft}$ off to allow time for the turbo-compressors to spool up

For subsonic cruise, (3), (turbo compressors inoperative), the TBE engines are throttled back to about 25 percent of maximum dry power and no compressor air is bypassed During climb and combat, (4), the TBE engines are operated at maximum power and at intermediate afterburning power for supersonic dash. For the vertical landing, the main engine maximum dry thrust is directed downward at a $90^{\circ}$ angle with the turbo compressor operating at maximum afterburning power

The varlous operational modes of the TBE/(TC.STOVL \& cruise) are depicted in figure 4 Since the turbo-compressor is used at all times, the bypass air is "on" at all times to power the turbo.-compressor During the takeoff ro11, (1), the TBE engines are at maximum power and the turbo-compressor thrust is directed aft at maximum afterburning power At lift.-off,(2), the main engine nozzle is directed at a downward angle The turbo compressors are still at maxi. mum afterburning power and the thrust is diverted downward by a ventral nozzle At subsonic cruise, (3), the TBE engines and the turbocompressors are throttled back During climb and combat, the main engines and the turbocompressors are at maximum power for vertical landing, (5), the main engine maximum dry thrust is diverted downward and the turbo-compressor maximum afterburning thrust is directed downward by the ventral nozzle

\section{METHOD OF ANALYSIS}

The study reflects differences in engine thrust and SFC, and nacelle and engine weights Mission performance calculations were made to determine mission radius and combat time for a fixed takeoff weight and payload

The mission is for a deck launched intercept type aircraft with a Mach 2 supersonic dash capability

The mission profile is shown in figure 5

The total radius calculated is the total of climb/acceleration, cruise and letdown ranges Fuel reserves inciude an enroute contingency of 5 percent of the mission fuel and provision for a 10 minute loiter

The airplane used in the study is a twin boom fighter design from NASA. Langley Two versions of the airplane were studied In figure 6 , the airplane is equipped with the TBE/(TC..STOVL only) engines in which the turbo. compressors are used for lift only As shown in the figure, the two turbo..compressors are located between the two TBE engines with inlet doors on the top of the fuselage and exhaust doors on the fuselage underside. The airplane used for the TF/RALS is the same as shown in figure 6 with the TBE/(TC-STOVL only) engines replaced by the TF/RALS system. The nacelle weight and volume were adjusted to accommodate differences in engine size In figure 7 the airplane is equipped with the TBE/(TC.STOVL \& cruise) engines in which the turbo-compressors are operated for the entire mission As shown in the figure, the turbo-compressors are located outboard of the main TBE engines in separate compartments The nacelle weight and volume were adjusted for the TBE engines and the added volume and weight for the turbo compressors These weight penalties were charged to the propulsion system. 
Engine cycle and sizing optimization studies have, as yet, not been completed for the purposes of this preliminary study cycle parameters were selected that would result in representative engines for this application. The engines were sized for a thrust loading ( $F / W G$ ) of 11 which is considered to be a reasonable value of thrust for this mission The engine characteristics are shown in Table I

The installed engine performance for the three systems was computed with the engine cycle computer code of reference 7 which performs cycle calculations, design, and off-design on a component by component basis Installation losses include inlet and nozzle drags

Baseline engine weights for the turbine bypass engines, the mixed flow turbofan and the turbo.-compressor were obtained from the study reported in reference 3 The final report of this study will be avallable in the near future The base line engine weights and dimensions were scaled for the engine sizes computed in this study

\section{RESULTS AND DISCUSSION}

Engine Performance and Weight - As mentioned previously, all of the engines are sized for a sea level static thrust to airplane gross weight ratio of 71 (51700 lbf) The resulting sea level static engine airflows are shown in Table I A comparison of the performance of these engines at Mach 0.8 is shown in figure 8 For the combat maneuver, minimum SFC at maximum thrust is a critical element in terms of combat time As shown in the figure, all three engine have about the same maximum thrust at this flight condition It should be emphasized that for the TBE/TC-STOVL \& cruise) system, the TBE engines are dry and the turbo compressors are at maximum afterburn The turbofan and the TBE main engines for the TF/RALS and the TBE/(TC.STOVL on Ty) systems are at maximum afterburning power The maximum power SFC of the turbofan is about 25 percent higher than that of the TBE/(TC-STOVL on $7 y$ ) and about 35 percent higher than that of the TBE/(TC-STOVL \& cruise) system As will be shown later, this has a large impact on the combat time capabilities of these airplanes As mentioned in the Introduction, one of the attractive features of the TBE is its efficient performance for wide variations in power settings As seen in figure 8 , the TBE engines are operating at 25 percent of maximum dry power for cruise and the turbofan operates at about 38 percent of maximum dry power The SFC's of the three systems are about the same at this operating condition The TBE/(TC-STOVL \& cruise) system SFC is about 3 percent higher than that of the TBE/TC..STOVL only) systems and about 5 percent higher than the TF/RALS system

Figure 9 shows the Mach 2 engine performance of the three systems The TF/RALS achieves the highest maximum thrust, but its SFC is 20 percent higher than the TBE systems At the cruise power setting, the SFC of the TBE/(TC-STOVL \& cruise) system is about 2 percent higher than that of the TBE/(TC-STOVL only) system and 4 percent lower than that of the TF/RALS system
As also mentioned in the Introduction. another motivation in exploring the TBE/TC systems is the possibility of reducing the overall propulsion system weight This is accomplished by reducing the size and weight of the main engines having a $F / W_{\text {eng }} \sim 8$ and obtaining the additional required thrust from the turbocompressor having a $F / W_{\text {eng }} \sim 18$ As seen in Table $I$, the sea level static airflow of the $\mathrm{TBE} /(\mathrm{TC}-\mathrm{STOVL}$ \& cruise) (Wa $=190 \mathrm{lbm} / \mathrm{sec}$ ) is the smallest of the three systems investigated The reduction in the overall propulsion system weight is shown in figure 10 In this figure, a comparison of the aircraft weight breakdown is shown for the three engine systems The TBE/(TC..STOVL \& crulse) propulsion system weight is the lowest of the three systems It is about 24 percent less than the weight of the TF/RALS and about 40 percent less than the TBE/(TC.STOVL only) system. Since the takeoff gross weight is the same for all three alrplanes, the TBE/(TC STOVL \& cruise) airplane can carry 11 percent more fuel than the TF/RALS airplane and 20 percent more fuel than the TBE/(TC.-STOVL only) airplane

Mission studies It was shown in figures 8 and 9 that the subsonic and supersonic SFC's at the cruise operating points are about the same for all three propulsion systems The fuel consumed during the cruise parts of the mission, therefore, is about the same for the three sys tems The differences between the three systems in terms of mission radius and combat time for this mission are the differences in the amount of fuel available for combat and the maximum power SFC Figure 11 shows the combat fuel allowance for the three propulsion systems As mentioned before, figure 10 shows the TBE/(TC..STOVL \& cruise) propulsion system weight is much less than the other two systems This results in a much higher combat fuel allowance as shown in figure 11 The combat fuel allow. ance for TBE/(TC.-STOVL \& cruise) system is 50 percent higher than the other two at a $100 \mathrm{~N} . \mathrm{Mi}$ radius and 150 percent higher at a 300 N Mi radius Even though the TF/RALS total fuel load is somewhat higher than that of the TBE/(TC.-STOVL only) airplane (figure 10), the combat fuel allowance is about the same because more climb/ acceleration fuel is required for the TF/RALS than for the TBE/(TC.-STOVL only)

Figure 12 compares the combat time and mis sion radius of the three systems since the TBE/(TC-STOVL \& cruise) system has a better combat SFC (figure 8) and much more fuel aval1. able (figure 11) than the other two systems, its combat time capability is much longer Its combat time is about 50 percent longer for the lower mission radius and 4 times longer at the higher radius The TBE/(TC.-STOVL oniy) system has a 25 percent advantage over the TF/RALS in terms of combat time. This is because the TBE/(TC-STOVL only) system has a better combat SFC (figure 8 ) and the two atrplanes have the same combat fuel allowance (figure 11)

\section{CONCLUDING REMARKS}

The mission results of this study show that large improvements in combat time (50 to 400 percent) can be achieved by the TBE/turbo- 
compressor if the turbo-compressor is used for both STOVL operations and thrust for the rest of the mission When the turbo-compressor is used for STOVL only, the TBE/turbo-.compressor would improve the combat time by about 25 percent compared to a TF/RALS system

The engine performance studies show that the TBE engines have better combat performance than a mixed flow afterburning turbofan. They have about the same performance during subsonic and supersonic cruise if the engines are sized for high thrust loading ( $F / W G$ ) For low thrust loading, the TBE engines would have better supersonic crutse performance and about the same subsonic cruise performance as the turbofan.

The preliminary nature of this study neces. sitated the use of approximate methods expecially in estimating the weight of the turbo-compressor and changes to the aircraft structure, weight, and aerodynamics which may be somewhat opti. mistic However, considering the large benefits promised by this system, it is believed that these benefits may be reduced somewhat if more exact methods are used, but would still be obtainable

In addition to the technology advances projected for future engines in materials, cooling, controls, etc, two key technologies unique to the TBE/(TC..STOVL \& cruise) system are in the turbine bypass system and the turbo-.compressor The effect of varying airflows on combustor and turbine performance has to be studied A turbocompressor such as the one used in this study would be a relatively new concept Most of the past work on remote fans has been for dedicated lift or auxilitary power in contrast, this turbo-compressor would be part of the main powerplant operating over a wide range of flight conditions

Future studies planned for the TBE/turbocompressor engines include engine cycle optimi. zation; TBE/(TC..STOVL \& cruise) systems in which the TBE's are equipped with afterburners and $\mathrm{TBE} /(\mathrm{TC}-\mathrm{STOVL} \&$ cruise) systems in which the turbo-compressors are limited to subsonic flight conditions Additional studies would also include dry turbo-compressors for a cool footprint This would also alleviate the impact of inlet reingestion on the engine operation since the exhaust gas would be much cooler compared to an afterburning lift system or a dedicated ifft engine

\section{REFERENCES}

1 Foley, W. H., Sheridan, A E and Smith, C W. "Study of Aerodynamic Technology for Single-Cruise-Engine V/STOVL. Fighter/Attack Aircraft, Phase I, "General Dynamics Corp., Fort Worth, TX, Feb, 1982 (NASA CR-166268)

2. Fishbach, L, $H$ and Franciscus, $L$ C , "A Remote Augmentor Lift System With a Turbine Bypass Engine," NASA TM-82932, 1982

3 Sheridan, A E , "The Application of Turbine bypass Engines to High Performance V/STOL Aircraft," AIAA Paper 83-2512, Oct 1983

4 Luidens, R. W. Turney, G. E and Allen, $J$, "Comparison of Two Parallel/Series Flow Turbofan Propulsion Concepts for Supersonic V/STOL," AIAA Paper 81-2673, Dec 1981

5 Griffin, D E, "Supersonic V/STOL-Tandem Fan Concepts," AIAA Paper 83-2567, Oct 1983

6 Franciscus, L C, "Turbine Bypass EngineA New Supersonic Cruise Propulsion Concept," NASA TM-82608, 1981

7 Fishbach, $L H$ and Caddy, $M J$, "NNEP The Navy-NASA Engine Program," NASA TM X-71857, 1975 
TABLE I - ENGINE CHARACTERISTICS

\begin{tabular}{|c|c|c|c|c|}
\hline Characteristic & $\begin{array}{c}\text { TBE/TC } \\
\text { STOVL onty }\end{array}$ & TC & $\begin{array}{c}\text { TBE/TC } \\
\text { STOYL \& Cruise }\end{array}$ & TF/RALS \\
\hline $\begin{array}{l}\text { BPR } \\
\text { FPR } \\
\text { OPR } \\
\text { CET max, R } \\
\text { TAUG max, R } \\
\text { F/WENG } \\
\text { F/WG } \\
\text { Wa }\end{array}$ & $\begin{array}{r}0.30 \\
20.0 \\
3500 \\
3960 \\
\text { a } 8.0 \\
c_{7} 1 \\
230\end{array}$ & \begin{tabular}{c}
20 \\
3.0 \\
-0 \\
\hdashline 3960 \\
18.0 \\
-80
\end{tabular} & 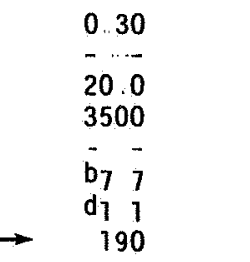 & $\begin{array}{rl}1 & 0 \\
3 & 5 \\
20.0 \\
3500 \\
3960 \\
\mathbf{a}_{8} .0 \\
\text { C }_{1} 1 \\
275\end{array}$ \\
\hline
\end{tabular}

aMain engines afterburning, turbo-compressors not open bMain engines dry; turbo-compressors afterburning; with ma in engines afterburning also $F / W G=9.0$

CMax axial thrust of main engines

dMax axial thrust of main engines and turbo-compressors 


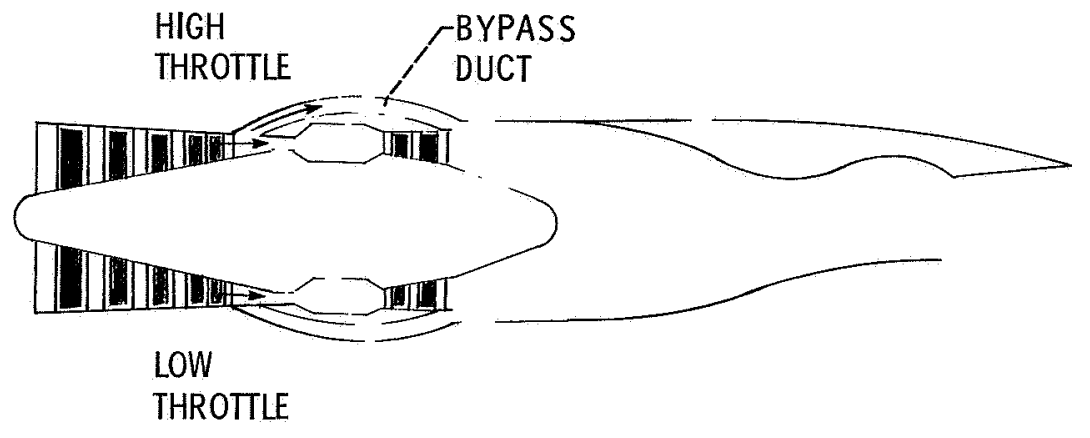

Figure 1. - Turbine bypass engine.

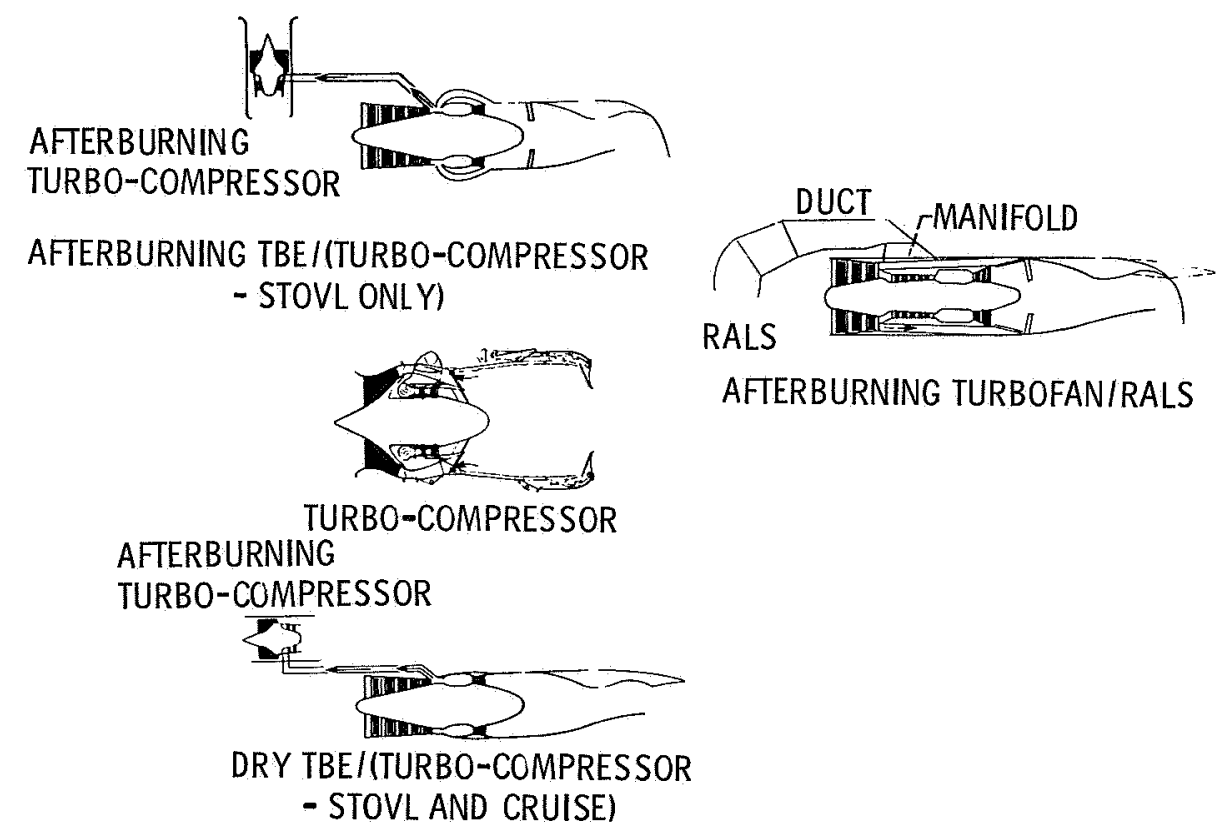

Figure 2 - STOVL propulsion systems. 


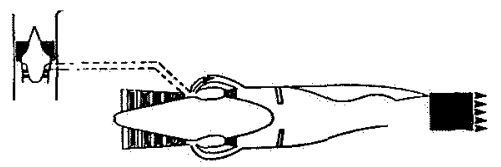

1. RUNWAY ACCELERATION

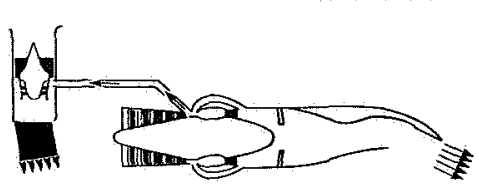

2. LIFT-OFF

$1 \rightarrow--m->-m--m-21$ DRY

4. COMBAT, SUPERSONIC CRUISE

AFTERBURNING

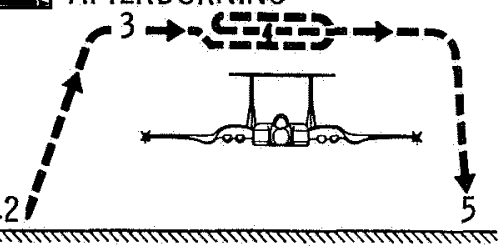

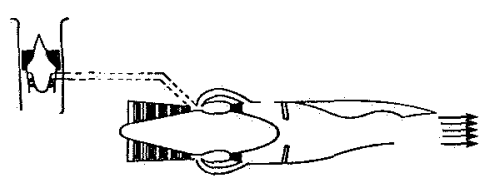

3. SUBSONIC CRUISE

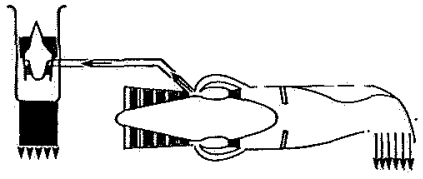

5. VERTICAL LANDING

Figure 3. - TBE/turbo-compressor lift engine propulsion modes for supersonic STOVL.
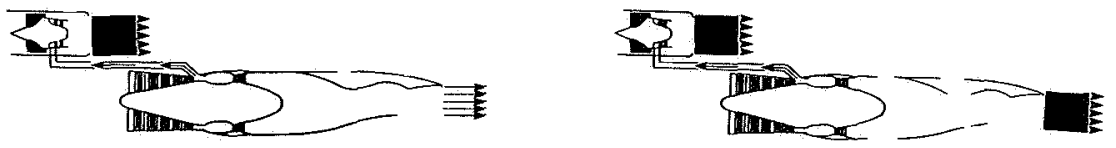

1. RUNWAY ACCELERATION DRY COMBAT, SUPERSONIC CRUISE

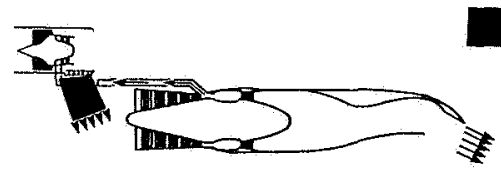

2. LIFT-OFF

AFTERBURNING

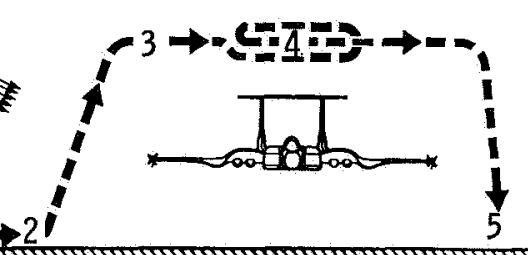

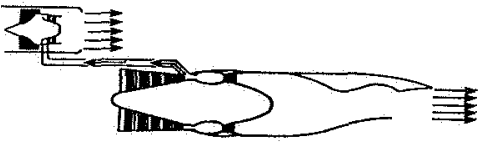

3. SUBSONIC CRUISE

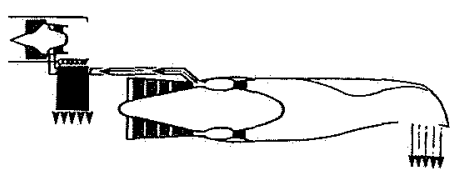

5. VERTICAL LANDING

Figure 4. - TBE/turbo-compressor lift and cruise engine propulsion modes for supersonic STOVL 


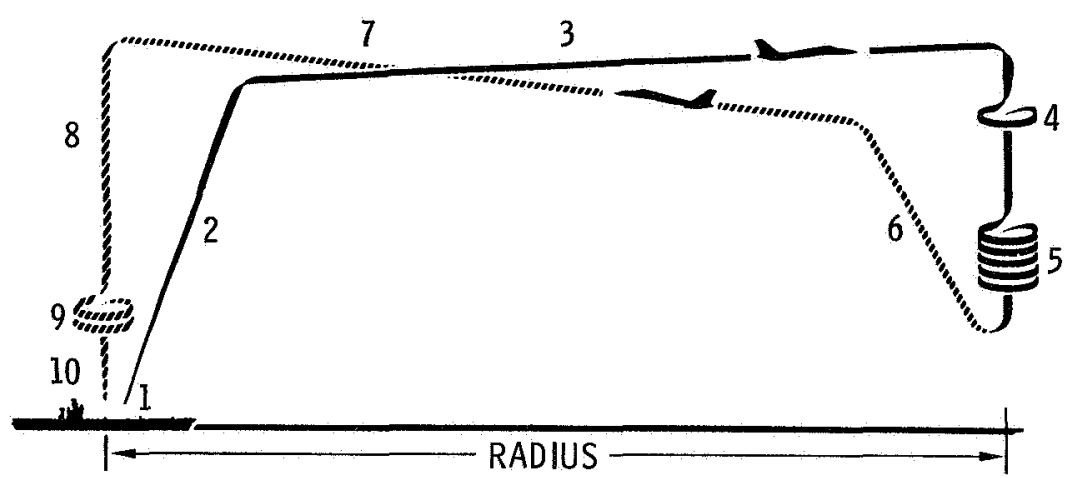

1. SHORT TAKEOFF

2. CLIMB; MAXIMUM POWER

3. CRUISE; MACH 2; OPTIMUM ALTITUDE

4. 1/2 TURN; MACH 2; $50000 \mathrm{ft}$

5. COMBAT; MAXIMUM POWER; MACH $0.8 ; 21000 \mathrm{ft}$

6. CLIMB; MAXIMUM POWER

7. CRUISE; MACH 0.8; OPTIMUM ALTITUDE

8. DESCENT

9. LOITER $10 \mathrm{~min} ; \mathrm{MACH} 0.45 ; 15000 \mathrm{ft}$

10. VERTICAL LAND

RESERVES - $10 \mathrm{~min}$ LOITER AND 5 PERCENT MISSION FUEL

PAYLOAD - $4600 \mathrm{lbm}$

Figure 5. - Mission profile. 


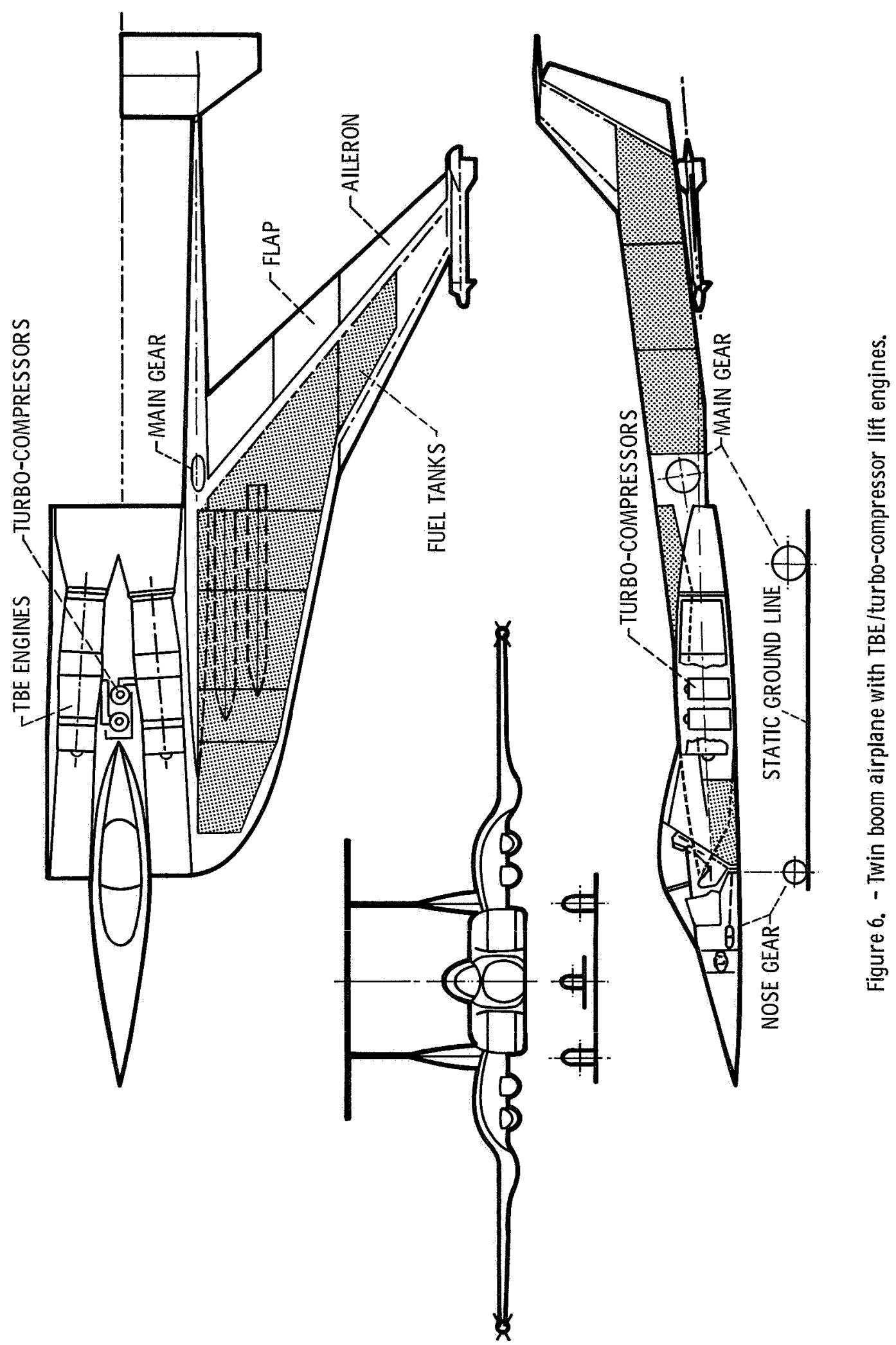




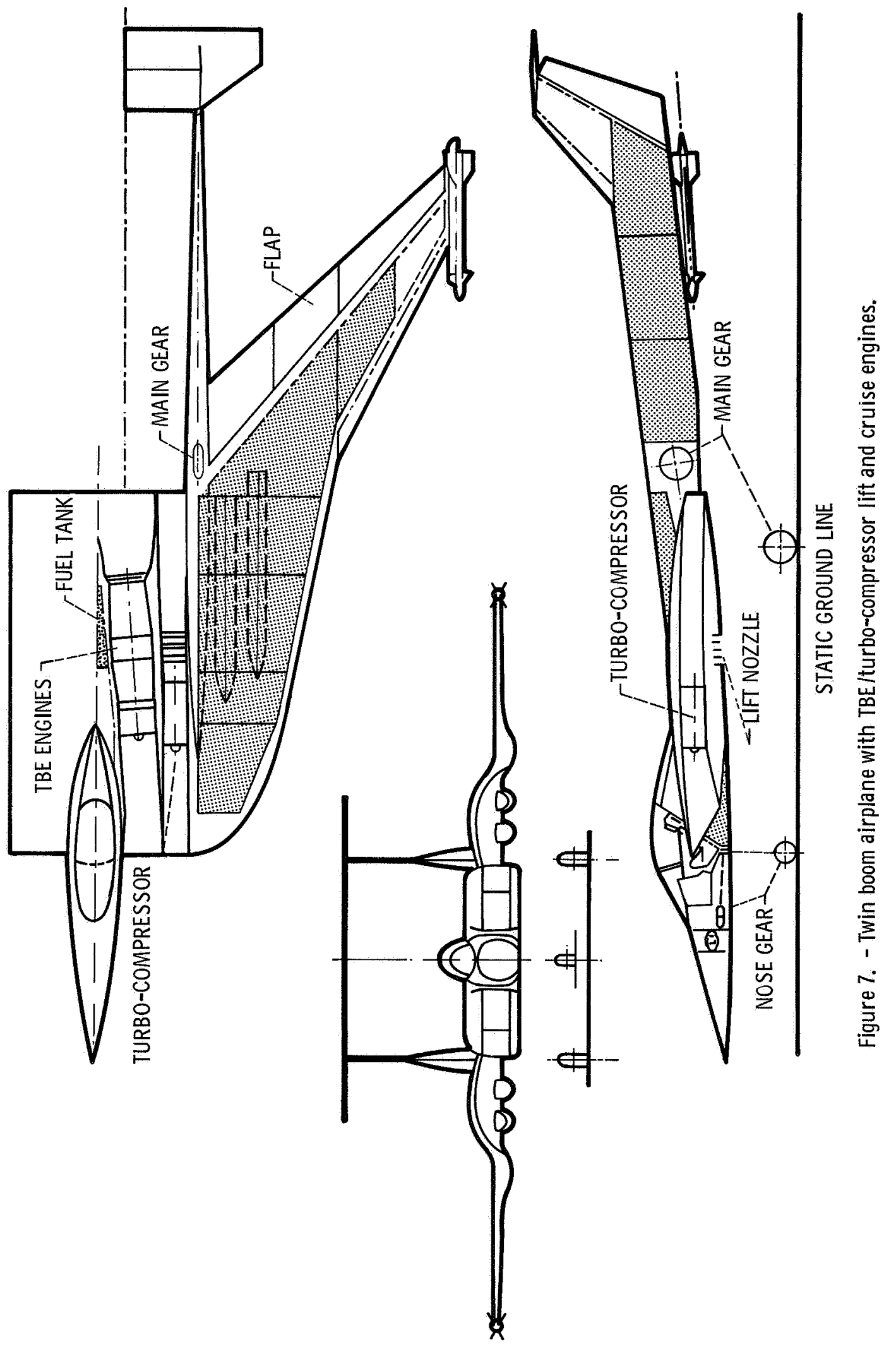




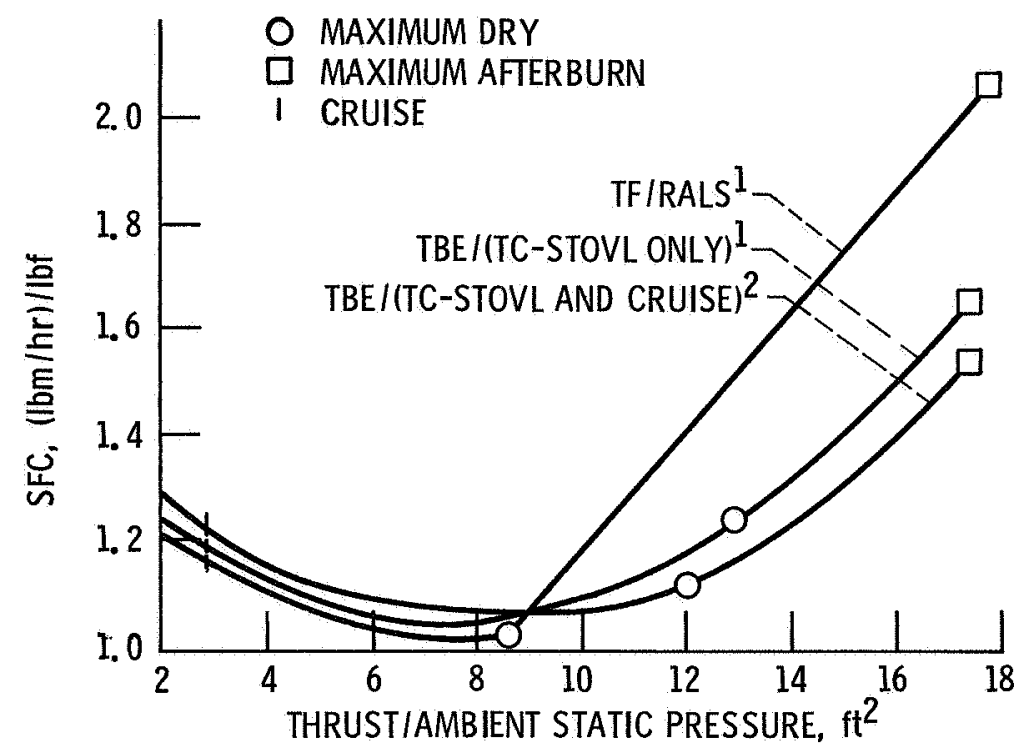

Figure 8. - Engine performance comparisons at Mach 0.8; sea level static thrust/takeoff gross weight, 1.1. Notes: 1. main engine afterburning ; 2 . main engine dry, turbo-compressor afterburning.

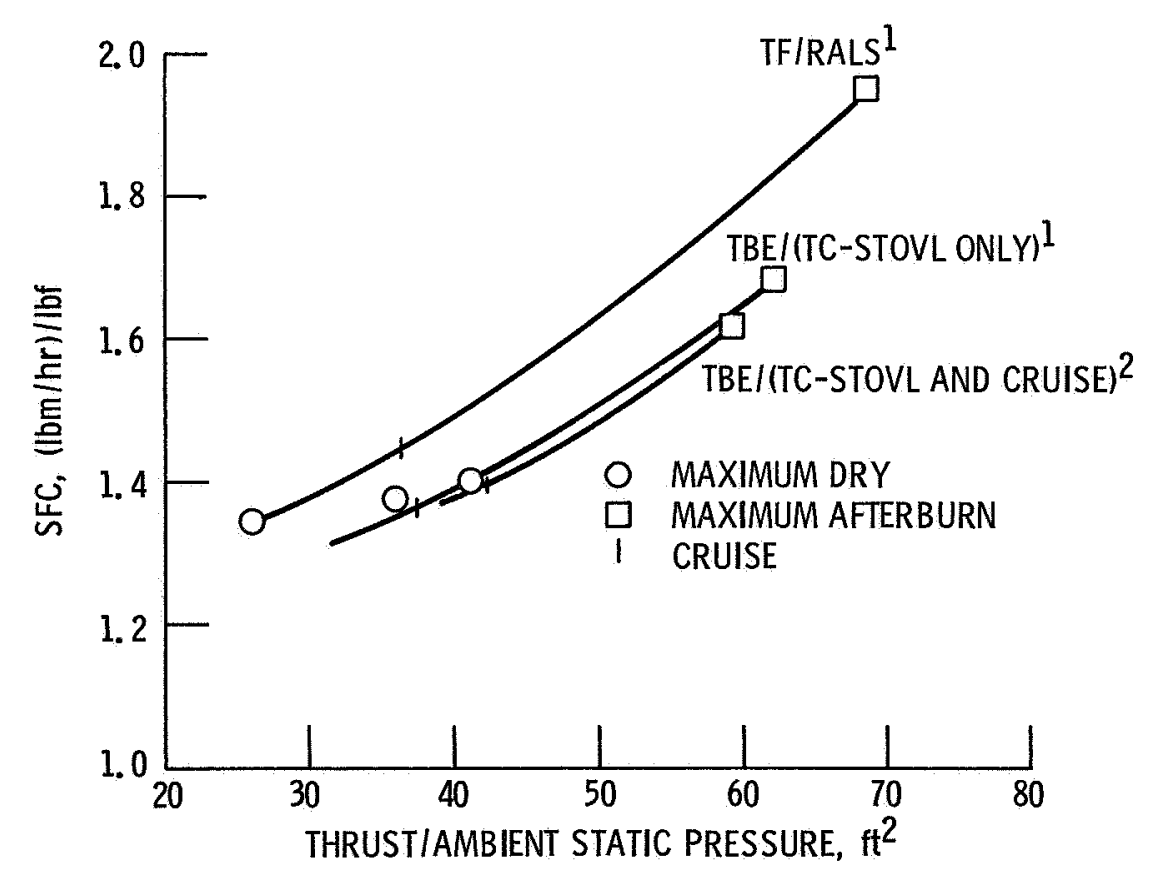

Figure 9. - Engine performance comparisons at Mach 2.0; sea level static thrust/takeoff gross weight, 1.1. Notes: 1. main engine afterburning; 2 . main engine dry, turbo-compressor afterburning. 


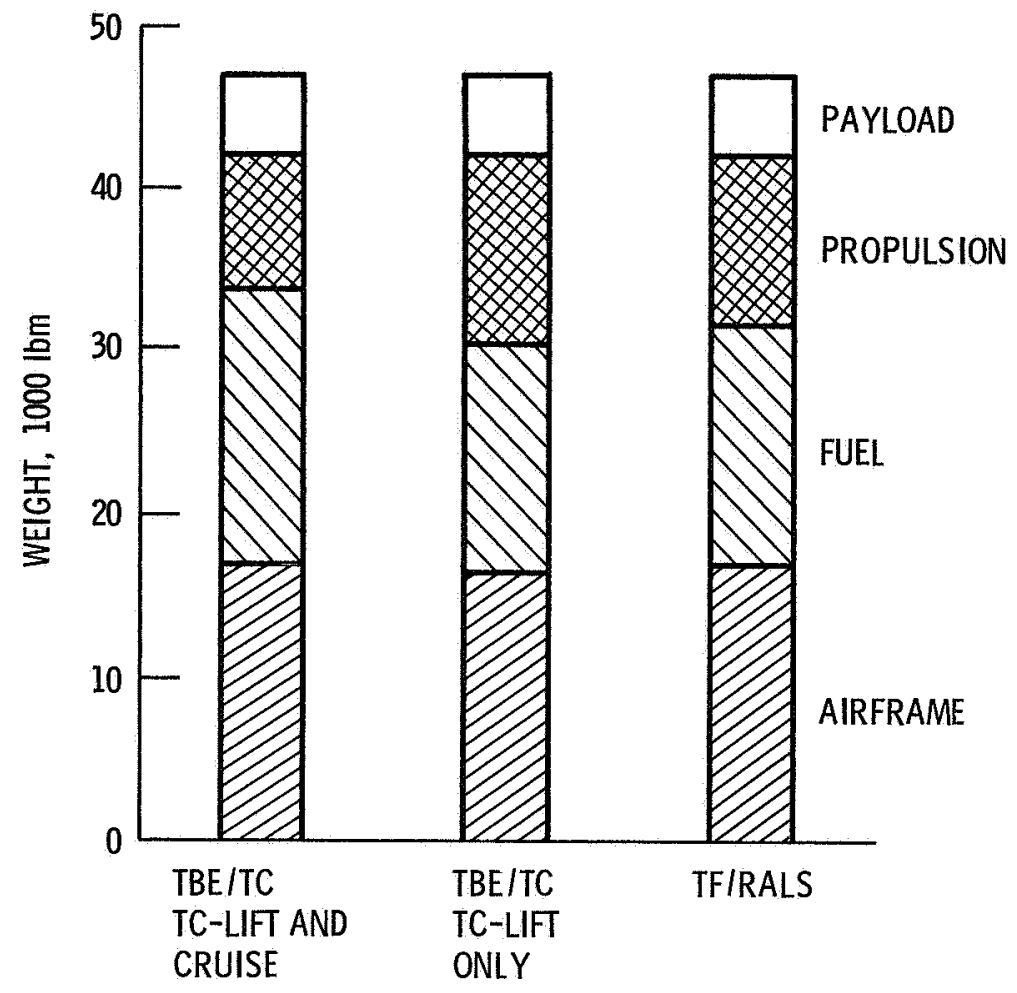

Figure 10. - Aircraft weight breakdown comparisons; takeoff gross weight, $47000 \mathrm{lbm}$; sea level static thrust/takeoff gross weight, 1.1.

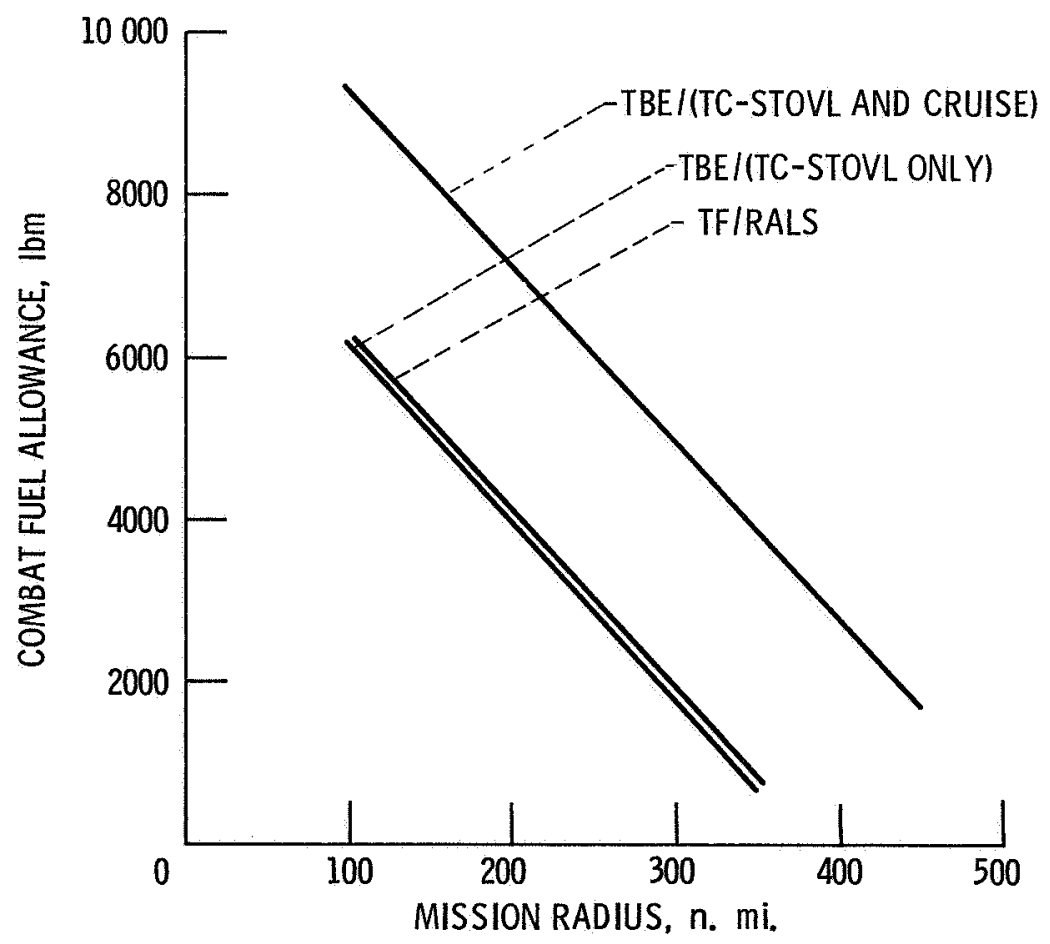

Figure 11. - Comparison of fuel available for combat; takeoff gross weight, $47000 \mathrm{lbm}$; sea level static thrust/ takeoff gross weight, 1.1. 


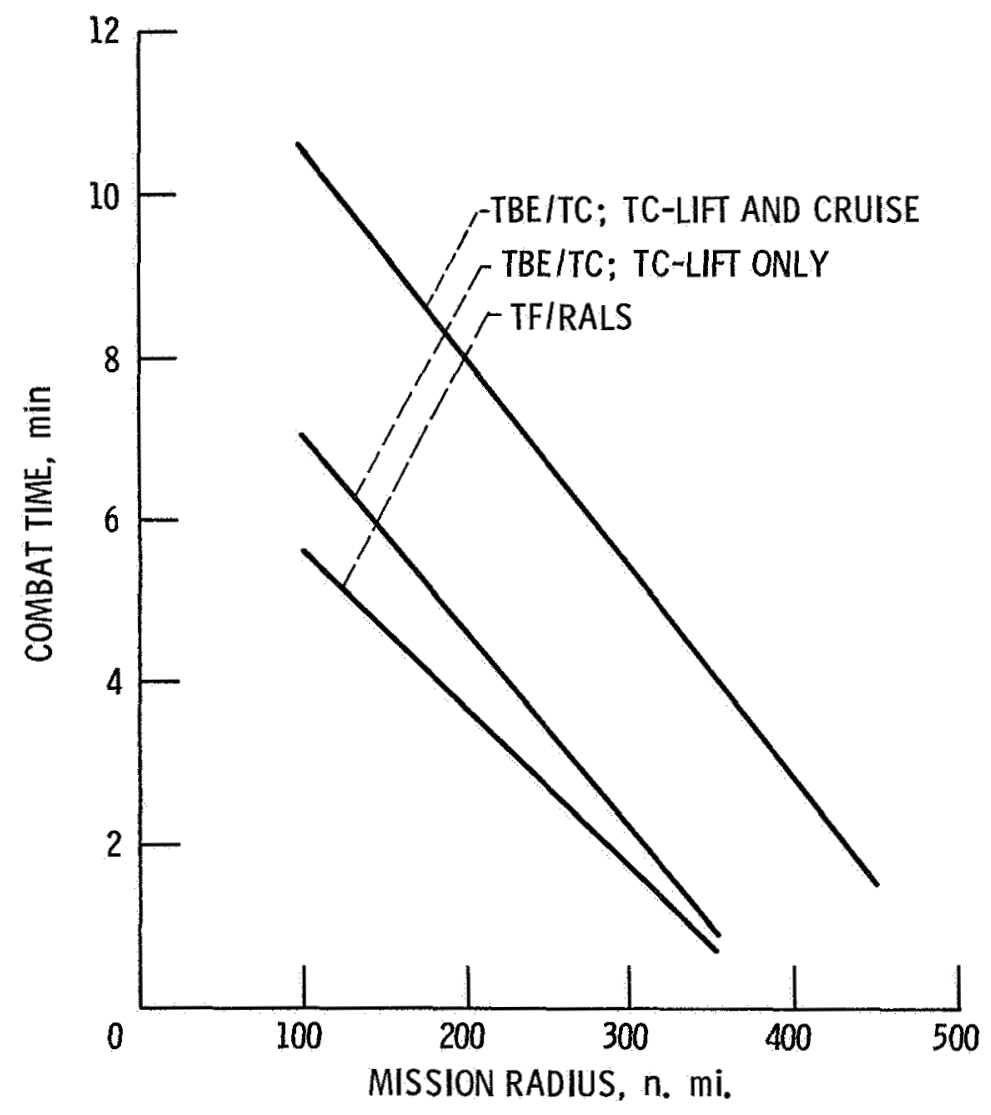

Figure 12. - Combat time versus mission radius; Mach 0.8; $20000 \mathrm{ft}$ combat; gross weight, $47000 \mathrm{lbm}$; sea level static thrust/gross weight, 1.1 . 


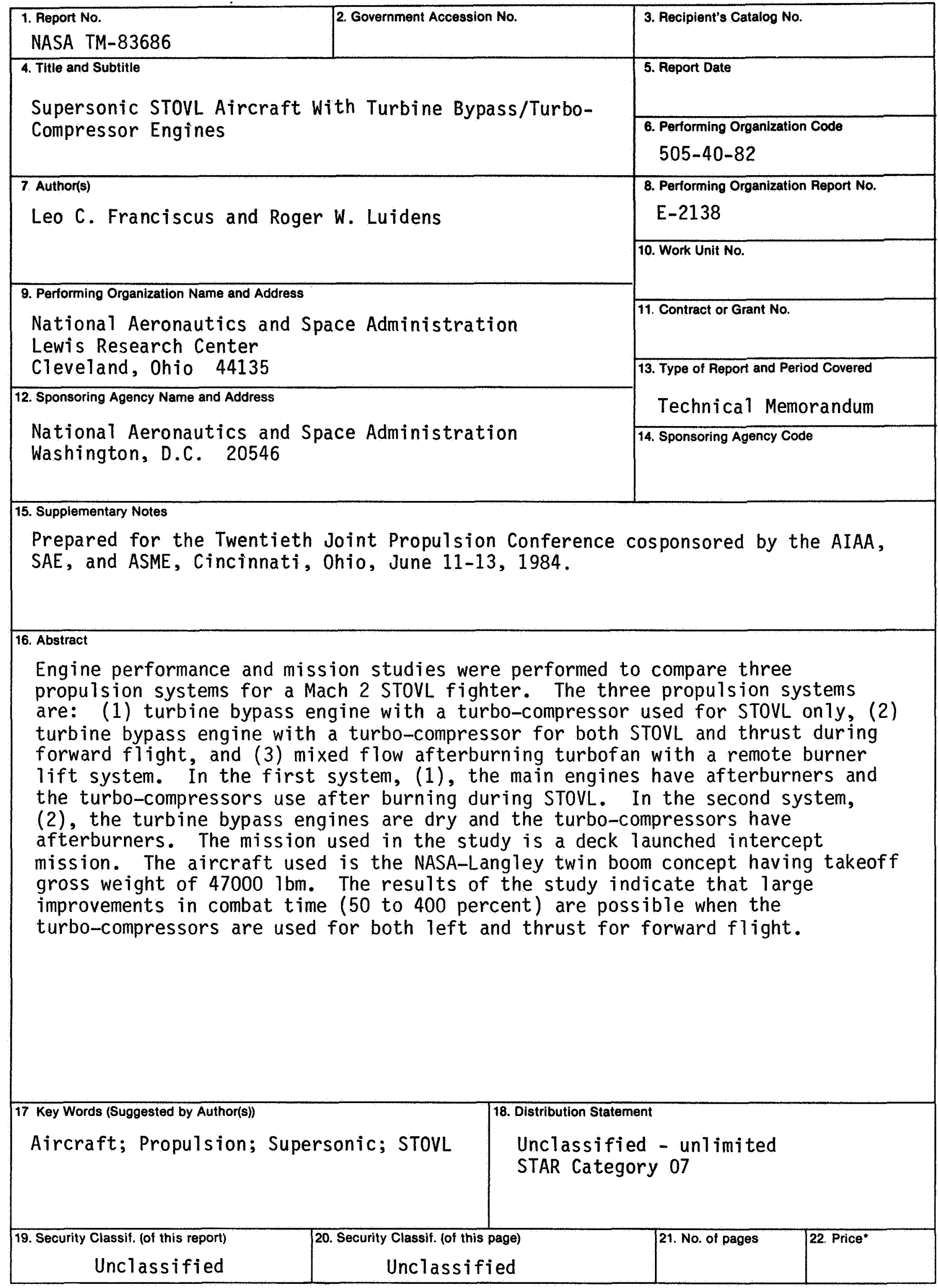

*For sale by the National Technical Information Service. Springfield, Virginia 22161 